\title{
Hepatic metabolism of glucose and linoleic acid varies in relation to susceptibility to fatty liver in ad libitum-fed Muscovy and Pekin ducks
}

\author{
Gladys Saez ${ }^{1}$, Elisabeth Baéza ${ }^{2}$, Stéphane Davail ${ }^{1}$, Denys Durand ${ }^{3}$, Dominique Bauchart ${ }^{3}$ \\ and Dominique Gruffat ${ }^{3 *}$ \\ ${ }^{1}$ IPREM-EEM, IUT des Pays de l'Adour, 371 rue du ruisseau, BP 201, 40004 Mont de Marsan Cedex, France \\ ${ }^{2}$ INRA, UR 83 Recherches Avicoles, F-37380 Nouzilly, France \\ ${ }^{3}$ INRA, UR 1213 Herbivores, Site de Theix, F-63122 St-Genès-Champanelle, France
}

(Received 19 December 2007 - Revised 23 May 2008 - Accepted 27 May 2008 - First published online 11 July 2008)

\begin{abstract}
The susceptibility to develop hepatic steatosis is known to differ between duck species, especially between Muscovy and Pekin ducks. This difference could be explained by either differential responses of species to overfeeding or genetic differences in hepatic lipid metabolism. The aim of the present study was to compare the intensities of the different hepatic pathways (oxidation, lipogenesis, esterification, secretion, etc.) of the two main nutrients (glucose and linoleic acid (LA)) reaching the liver of ad libitum-fed Muscovy $(n 6)$ and Pekin ( $n$ 6) ducks using the ex vivo method of liver slices incubated for $16 \mathrm{~h}$ with $\left[\mathrm{U}-{ }^{14} \mathrm{C}\right]$ glucose, $\left[1-{ }^{14} \mathrm{C}\right] \mathrm{LA}$ and $\left[{ }^{35} \mathrm{~S}\right]$ methionine added to the survival medium. In such experimental conditions, the lipogenesis pathway from glucose was 2 -fold higher $(P<0 \cdot 05)$ in the liver of the Muscovy duck than in that of the Pekin duck. Furthermore, the hepatic uptake of LA was 2-fold higher $(P<0.05)$ in the Muscovy duck than in the Pekin duck leading to a 2-fold higher $(P<0.05)$ esterification of this fatty acid in the liver of the Muscovy duck. The hepatic secretion of VLDL was higher $(P<0 \cdot 01)$ in the Muscovy duck than in the Pekin duck but insufficient to prevent lipid accumulation in the liver of the Muscovy duck. In conclusion, these results show the influence of the species on the hepatic metabolism of ducks in relation to their susceptibility to develop fatty liver. These results should shed light on the metabolic regulations that might underlie susceptibility to hepatic steatosis in the the human liver.
\end{abstract}

Glucose: Linoleic acid: Duck: Liver: Metabolism

Hepatic steatosis occurs widely in man and animal species as a response to various forms of acquired or inherited metabolic disorders. Wild migrating species of birds can spontaneously develop a hepatic steatosis as a consequence of energy storage to permit migration ${ }^{(1)}$. This process is facilitated in these species because the liver is the major site for de novo lipogenesis in birds ${ }^{(2)}$. In domestic palmipedes (i.e. ducks and geese), this specific capacity is exploited for the commercial production of fatty liver (foie gras). Duck species can therefore be used as a model to study the mechanisms inducing hepatic steatosis. In a general way, hepatic steatosis results from an imbalance between synthesis and secretion of TAG as parts of lipoproteins (mainly VLDL) by the liver. The regulation of TAG synthesis occurred at two major intracellular branch points: (1) the partition of fatty acids (FA) between the esterification and oxidation pathways; (2) the conversion of diacylglycerols into TAG or phospholipids (PL). On the other hand, VLDL production requires the availability of TAG at their site of assembly with apoB in the endoplasmic reticulum ${ }^{(3)}$. However, microsomal TAG represented only a small part of total cellular TAG compared with the cytosolic TAG storage pool ${ }^{(4)}$. The participation of stored TAG to VLDL packaging needs to follow a hydrolysis-re-esterification process to reach the endoplasmic reticulum into which VLDL assembly proceeds. However, the specific mechanisms of dietary-induced fatty liver in palmipedes remain puzzling. Indeed, metabolic response to overfeeding varies considerably and depends, among other factors, on species and breed, which may be indicative of a genetic determinism. Thus, in the two species of domesticated ducks, the European native common duck (Pekin, Anas platyrhynchos) and the American native duck (Muscovy, Cairina moschata), the degree of overfeeding-induced hepatic steatosis is higher in the Muscovy duck than in the Pekin duck ${ }^{(5-7)}$

Some scientists have attempted to explain these genetic differences in fat metabolism by quantifying plasma metabolites and activities of key enzymes of the hepatic lipogenesis using glucose as a precursor. Baéza et al. ${ }^{(8)}$ reported a higher enzyme activity for acetyl-CoA carboxylase and FA synthase in the Muscovy duck than in the Pekin duck, suggesting a higher ability for lipid synthesis in the Muscovy species. By contrast, plasma VLDL concentration was lower in the Muscovy duck than in the Pekin $\operatorname{duck}^{(5)}$, and the authors suggested a lower ability of the liver to secrete TAG-rich lipoprotein in Muscovy species. All these results are consistent with the higher ability of the Muscovy duck to develop hepatic steatosis as mentioned earlier ${ }^{(5,6)}$. 
In this context, the aim of the present study was to compare the hepatic fat metabolism of Muscovy and Pekin ducks fed ad libitum with a growing diet rich in maize (the main component of overfeeding diet) by quantifying directly the hepatic ability for lipid synthesis and lipid secretion. For this purpose, we used an in vitro method of incubated liver slices in the presence of $\left[1-{ }^{14} \mathrm{C}\right]$ linoleic acid (LA, the main FA present in maize), [U- $\left.{ }^{14} \mathrm{C}\right]$ glucose (the main energetic substrate present in maize) or $\left[{ }^{35} \mathrm{~S}\right]$ methionine (a marker of apoB synthesis, the main structural protein of VLDL particles) in order to quantify the incorporation of these radiolabelled substrates in neo-synthesised lipids and/or VLDL after $16 \mathrm{~h}$ of incubation in the survival medium.

\section{Materials and methods \\ Chemicals and materials}

The survival medium used for liver-slice incubation (RPMI-1640 and methionine-cysteine-free RPMI-1640), bovine serum albumin free of FA and the antibiotic-antimycotic cocktail were purchased from Sigma Chemical (St Louis, MO, USA). $\left[1{ }^{14} \mathrm{C}\right] \mathrm{LA}$ (2.04 GBq/mmol), [U- $\left.{ }^{14} \mathrm{C}\right]$ glucose $(10.4 \mathrm{GBq} / \mathrm{mmol}),\left[{ }^{35} \mathrm{~S}\right] \mathrm{meth}-$ ionine $(37 \mathrm{TBq} / \mathrm{mmol})$, glycerol tri $\left[9,10(n)-{ }^{3} \mathrm{H}\right]$ oleate $(0.74 \mathrm{TBq}$ mmol) and L-3-phosphatidyl $\left[\mathrm{N}\right.$-methyl- $\left.{ }^{3} \mathrm{H}\right]$ choline-1,2-dipalmitoyl $(2.4 \mathrm{TBq} / \mathrm{mmol})$ were purchased from Amersham International (Bucks, UK). Hyamine hydroxide was from ICN Biochemicals (Irvine, CA, USA). Perchloric acid and solvents (chloroform, methanol, propanol, diethyl ether and acetic acid) were from Prolabo (Paris, France). Ready-Safe scintillation cocktail was from Beckman Instruments (Fullerton, CA, USA). Plastic organ culture Petri dishes were from Becton Dickinson (Cockeysville, MD). Plastic centre wells were from Kontes (Vineland, NJ, USA) and aminopropyl-activated silica Sep-Pak ${ }^{\circledR}$ cartridges were from Waters (Milford, MA, USA).

\section{Animals}

All experimental procedures were performed in accordance with the French National Guidelines for the care and use of animals for research purposes (Certificate of Authorisation to Experiment on Living Animals no. 7740, Ministry of Agriculture and Fish Products). This experiment was carried out using 1-d-old male ducks from two genera: Muscovy and Pekin. The animals were distributed into two groups (six per species) and reared under usual conditions of light and temperature at the Experimental Station for Waterfowl Breeding (INRA, Artiguères, France). All ducks were fed ad libitum for the whole experimental period. The chemical composition and main characteristics of starting and growing diets are presented in Table 1. Feed consumption was a mean value corresponding to the consumption of one group for each period (one pen per species). At 12 weeks of age, ducks were transferred to the Experimental Station of INRA Theix (URH, Clermont-Fd, France) and maintained on the same growing diet fed ad libitum for 1 week.

\section{Tissue preparation and liver-slice incubation}

The ducks were killed by sectioning the neck $2-4 \mathrm{~h}$ after meal, allowing comparable levels in plasma metabolites (glucose,
Table 1. Composition and main characteristics of diets

\begin{tabular}{|c|c|c|}
\hline $\begin{array}{l}\text { Composition } \\
(\mathrm{g} / \mathrm{kg})\end{array}$ & $\begin{array}{c}\text { Starting } \\
(0-4 \text { weeks })\end{array}$ & $\begin{array}{c}\text { Growing } \\
(4-13 \text { weeks })\end{array}$ \\
\hline Wheat & $200 \cdot 00$ & 254.50 \\
\hline Maize & 357.02 & $370 \cdot 48$ \\
\hline Sorghum & - & $80 \cdot 00$ \\
\hline Triticale & $100 \cdot 00$ & - \\
\hline Extruded soyabean seeds & $40 \cdot 00$ & $15 \cdot 00$ \\
\hline Rapeseed oil meal & $30 \cdot 00$ & $50 \cdot 00$ \\
\hline Soyabean meal & 184.75 & 138.75 \\
\hline Sunflower meal & $29 \cdot 00$ & 44.50 \\
\hline Sugarcane molasses & $20 \cdot 00$ & $15 \cdot 00$ \\
\hline Calcium carbonate & 13.50 & $10 \cdot 00$ \\
\hline Dicalcium phosphate & $17 \cdot 75$ & $15 \cdot 00$ \\
\hline Sodium chloride & 1.00 & 1.75 \\
\hline Sodium bicarbonate & 2.50 & 1.50 \\
\hline D,L-Methionine & 1.88 & $1 \cdot 12$ \\
\hline Choline- $\mathrm{HCl}, 75 \%$ & 0.60 & 0.40 \\
\hline Vitamin and mineral supplement & $2 \cdot 00$ & 2.00 \\
\hline \multicolumn{3}{|l|}{ Characteristics $(\mathrm{g} / \mathrm{kg})$} \\
\hline Metabolisable energy (MJ/kg) & $11 \cdot 83$ & 11.68 \\
\hline Crude protein & $175 \cdot 10$ & $160 \cdot 00$ \\
\hline Total lipids & $30 \cdot 40$ & $27 \cdot 40$ \\
\hline Lysine & $9 \cdot 20$ & $7 \cdot 80$ \\
\hline Sulphur amino acids & $7 \cdot 70$ & $7 \cdot 10$ \\
\hline Calcium & 11.00 & 9.00 \\
\hline Available phosphorus & 4.50 & 4.00 \\
\hline
\end{tabular}

insulin, NEFA, lipids and ketone bodies) between animals (data not shown). We alternated species after each duck was killed. Immediately after killing, the liver was excised, quickly rinsed in an ice-cold saline solution $(9 \mathrm{~g} \mathrm{NaCl} / \mathrm{l})$ and weighed. Then, it was trimmed of blood and connective tissue and a part of the organ was frozen and stored at $-20^{\circ} \mathrm{C}$ in order to determine hepatic DNA, total lipid contents and FA composition of total lipids. Another part of the liver was cut into thick slices of $0.5 \mathrm{~mm}$ (approximately $300 \mathrm{mg}$ of fresh liver) and placed on stainless steel grids positioned either on a plastic organ culture Petri dish or in a $25 \mathrm{ml}$ flask equipped with suspended plastic centre wells (for specific $\mathrm{CO}_{2}$ measurements) in the presence of RPMI-1640 medium supplemented with an antibiotic-antimycotic cocktail $(0.06 \mathrm{mg}(100 \mathrm{U}) / \mathrm{ml}$ penicillin, $0.1 \mathrm{mg} / \mathrm{ml}$ streptomycin and $0.25 \mu \mathrm{g} / \mathrm{ml}$ amphotericin) and with a mixture of FA $(1.5 \mu \mathrm{M}$ (14:0), 56.1 $\mu \mathrm{M}(16: 0), 30 \cdot 4 \mu \mathrm{M}(18: 0), 96 \cdot 6 \mu \mathrm{M}(18: 1 n-9)$ and $15.4 \mu \mathrm{M}(18: 2 n-6))$ complexed to bovine serum albumin (FA-albumin molar ratio 1:4) representative in composition and concentration of plasma total lipid of duck. The Petri dish and flask with the sample were placed for $3 \mathrm{~h}$ at $37^{\circ} \mathrm{C}$ under a water-saturated, $95 \% \mathrm{O}_{2}-5 \% \mathrm{CO}_{2}$ atmosphere to ensure cell recovery. The medium was then replaced with fresh RPMI1640 medium supplemented with an antibiotic-antimycotic cocktail and with an FA mixture in the presence of $\left[1-{ }^{14} \mathrm{C}\right] \mathrm{LA}$ $(111 \mathrm{kBq} / \mathrm{ml}),\left[\mathrm{U}_{-}{ }^{14} \mathrm{C}\right]$ glucose $(222 \mathrm{kBq} / \mathrm{ml})$ or $\left[{ }^{35} \mathrm{~S}\right]$ methionine $(5 \cdot 55 \mathrm{GBq} / \mathrm{ml})$. For the $\left[\mathrm{U}-{ }^{14} \mathrm{C}\right] \mathrm{glucose}$ labelling, the non-labelled glucose present in the medium was retained to maintain the physiological concentration of glucose. For the $\left[1-{ }^{14} \mathrm{C}\right] \mathrm{LA}$ labelling, the non-labelled LA present in the medium was removed to maintain the same concentration of LA as at the beginning of incubation. For the $\left[{ }^{35} \mathrm{~S}\right]$ methionine labelling, the medium did not contain non-labelled methionine. Liver-slice incubations, corresponding to a dish and a flask per animal, were stopped after $16 \mathrm{~h}$ of labelling. Therefore, media were collected and liver slices from each Petri dish and flask were washed with $2 \mathrm{ml}$ of saline-buffered 
solution $\quad(5.4 \mathrm{~mm}-\mathrm{KCl}, \quad 103.4 \mathrm{~mm}-\mathrm{NaCl}, \quad 11.1 \mathrm{~mm}$-glucose, $26.1 \mathrm{mM}-\mathrm{Na}_{2} \mathrm{HPO}_{4}, \quad 9.4 \mathrm{~mm}-\mathrm{NaH}_{2} \mathrm{PO}_{4}$ ) and homogenised in $2 \mathrm{ml}$ of $0.25 \mathrm{~mm}$-Tris- $\mathrm{HCl}(\mathrm{pH} 8)$ and $50 \mathrm{~mm}-\mathrm{NaCl}$ buffer with a Dounce homogeniser. In parallel, the viability of hepatocytes was verified by determining the glucose-6-phosphate dehydrogenase activity before and at the end of the incubation period (data not shown).

\section{Analysis of incubated liver slices}

Determination of $\left[\mathrm{U}_{-}{ }^{14} \mathrm{C}\right]$ glucose oxidation. The ${ }^{14} \mathrm{CO}_{2}$ produced by the liver slices was complexed with hyamine hydroxide $(150 \mu \mathrm{l})$ introduced into the suspended plastic centre wells inside flasks at the beginning of the time-course study. At the end of the incubation, the centre wells were placed into scintillation vials containing $4 \mathrm{ml}$ of the ReadySafe scintillation cocktail and the radioactivity was counted.

Determination of $\left[\mathrm{U}^{14} \mathrm{C}\right]$ glucose intervention into lipogenesis. Total liver lipids were extracted according to the method of Folch et al. ${ }^{(9)}$ and their corresponding FA were liberated and methylated by transmethylation at the room temperature according to the method of Sébédio et al. ${ }^{(10)}$. FA methyl esters and glycerol were separated by hexane extraction. The aqueous containing glycerol and the hexane containing FA methyl esters were evaporated under an air stream and counted for radioactivity.

Determination of $\left[U_{-}{ }^{14} \mathrm{C}\right]$ glucose incorporation into neutral and polar lipids. Total lipids were extracted according to the method of Folch et al. ${ }^{(9)}$ after the addition of a standard non-radioactive liver homogenate $(850 \mu \mathrm{l}$ containing approximately $10 \mathrm{mg}$ of lipids) as a lipid carrier and of $\left[{ }^{3} \mathrm{H}\right]$ triolein $(67 \mathrm{~Bq})$ and $\left[{ }^{3} \mathrm{H}\right]$ phosphatidylcholine $(100 \mathrm{~Bq})$ as internal TAG and PL standards. Lipid classes were then separated by solid-chromatography on an aminopropyl-activated silica Sep-Pak ${ }^{\circledR}$ cartridge according to the method of Kaluzny et al. ${ }^{(11)}$. Briefly, neutral lipids (mono-, di-, triacylglycerols, non-esterified and esterified cholesterol) were eluted by $6 \mathrm{ml}$ of chloroform-2-propanol $(2: 1, \mathrm{v} / \mathrm{v})$. NEFA were then eluted in $6 \mathrm{ml}$ of $2 \%$ acetic acid in diethyl ether. Finally, polar lipids (mainly PL) were eluted by $6 \mathrm{ml}$ of methanol. The lipid fractions were collected in scintillation vials, evaporated to dryness under an air stream and counted for radioactivity.

Determination of $\left[1-{ }^{14}\right.$ C]linoleic acid oxidation. As for the determination of glucose oxidation, the ${ }^{14} \mathrm{CO}_{2}$ produced by the liver slices incubated in the presence of $\left[1-{ }^{14} \mathrm{C}\right] \mathrm{LA}$ was complexed with hyamine hydroxide and the radioactivity was counted. The amount of produced ketone bodies was determined in both homogenate and medium. Briefly, lipids were extracted according to the method of Folch et al. ${ }^{(9)}$ and the aqueous containing mainly ketone bodies was counted for radioactivity.

Determination of $\left[1-{ }^{14}\right.$ C]linoleic acid esterification into neutral and polar lipids. $\quad\left[1-{ }^{14} \mathrm{C}\right] \mathrm{LA}$ esterification into neutral and polar lipids was quantified in the same way as that for $\left[\mathrm{U}_{-}{ }^{14} \mathrm{C}\right]$ glucose incorporation into lipids (as previously mentioned).

Total newly synthesised and secreted ${ }^{35}$ S-labelled proteins. Total proteins from cell homogenates and media were isolated by precipitation with ice-cold TCA, as previously described $^{(12)}$, and counted for radioactivity.

Newly synthesised and secreted $\left[{ }^{35}\right.$ S]apoB and $\left[{ }^{35}\right.$ S Jalbumin. $\mathrm{ApoB}$ and albumin were separated by electrophoresis on a continuous polyacrylamide gradient gel slab from 2.5 to $10 \%$ under denaturing conditions and isolated from Coomassie blue-stained gels, as previously described ${ }^{(10)}$.

${ }^{35}$ S JVLDL isolation. Three millilitres of medium were supplemented with purified duck VLDL ( $0.3 \mathrm{mg}$ of TAGVLDL) as a carrier, brought to a density of $1.063 \mathrm{~g} / \mathrm{l}$ with $\mathrm{KBr}$ and overlaid with $9 \mathrm{ml}$ of $\mathrm{KBr}$ solution (density $1.006 \mathrm{~g} / \mathrm{l}$ ). VLDL were purified by ultracentrifugal flotation at $100000 \mathrm{~g}$ for $16 \mathrm{~h}$ at $15^{\circ} \mathrm{C}$ in a Kontron Centrikon T-2060 ultracentrifuge with a TST 41-14 rotor. Floating VLDL were recentrifuged under the same conditions as previously mentioned except that pure albumin $(50 \mathrm{mg} /$ tube $)$ was added to remove traces of $\left[{ }^{14} \mathrm{C}\right] \mathrm{FA}$ or ${ }^{35} \mathrm{~S}$-labelled proteins adsorbed onto the VLDL particles. Finally, the purified VLDL were collected at the top of the tube (five fractions of $500 \mu \mathrm{l}$ ) and counted for radioactivity in scintillation vials.

\section{Hepatic DNA content}

The determination of DNA content of liver cells was performed according to the method described by Labarca \& Paigen $^{(13)}$. Briefly, total DNA was determined by fluorimetric analysis (356 and $458 \mathrm{~nm}$ for excitation and emission wavelengths, respectively) using calf thymus DNA $(5 \mu \mathrm{g} / \mathrm{ml})$ as a DNA reference.

\section{Composition of lipids in the liver}

Lipids were extracted according to the method of Folch et al. ${ }^{(9)}$ and the different classes of lipids were separated using an HPLC system equipped with a silica column of $5 \mu \mathrm{m}(4.6 \mathrm{~mm} \times 150 \mathrm{~mm}$; Waters $)$. Three different mobile phases were used: iso-octane-tetrahydrofurane $(99: 1, \mathrm{v} / \mathrm{v})$ to separate cholesterol esters; non-esterified cholesterol and NEFA; acetone-dichloromethane $(2: 1, \mathrm{v} / \mathrm{v})$ to separate TAG and 2-propanol-water-acetic acid-ethanol (85:15, v/v) to separate PL. Total cholesterol was estimated by adding non-esterified and esterified cholesterol.

\section{Statistical analysis}

Values are expressed as the means with their standard errors of six independent experiments. The effects of animal species (Muscovy $v$. Pekin ducks) were tested by ANOVA according to the general linear model procedure of SAS (SAS ${ }^{\circledR}$ Systems, Release 8.6; SAS Institute Inc., Cary, NC, USA).

\section{Results}

\section{Duck characteristics at slaughtering}

The total feed consumption tended to be higher for the Pekin duck than the Muscovy duck during the starting period (3.09 and $2.52 \mathrm{~kg} /$ duck, respectively; Table 2). During the growing period, Pekin and Muscovy ducks had a similar total feed consumption (approximately $22 \mathrm{~kg} / \mathrm{duck}$ for the whole experimental period).

Body and liver weights at slaughtering were 1.4- and $1 \cdot 9$-fold higher $(P<0 \cdot 0100)$ in the Muscovy duck than in the Pekin duck, respectively. These differences between species occurred with an increased content of total lipids in the 
Table 2. Zootechnical parameters and hepatic lipid composition of Muscovy and Pekin ducks at slaughtering

(Mean values with their standard errors for six ducks per group)

\begin{tabular}{lccc}
\hline & Muscovy & Pekin & SE† \\
\hline Live body weight at slaughtering $(\mathrm{kg})$ & 6.08 & $4.28^{* *}$ & 0.86 \\
Liver weight at slaughtering $(\mathrm{g})$ & 109.26 & $56 \cdot 25^{\star *}$ & 4.29 \\
Total lipids (mg/g fresh liver) & 78.6 & $34.0^{*}$ & 4.67 \\
TAG (mg/g fresh liver) & 49.3 & $5.6^{*}$ & 4.35 \\
PL (mg/g fresh liver) & 24.9 & 24.9 & 0.32 \\
Total cholesterol (mg/g fresh liver) & 2.3 & 1.9 & 0.07 \\
Other lipids (mg/g fresh liver) & 1.6 & 1.4 & 0.15 \\
DNA ( $\mu \mathrm{g} / \mathrm{mg}$ fresh liver) & 4.47 & $5.24^{*}$ & 0.22 \\
\hline
\end{tabular}

PL, phospholipids.

Mean value was significantly different from that of the Muscovy ducks: ${ }^{*} P<0.05$, ${ }^{\star *} P<0.01$.

$\dagger \mathrm{SE}=\sqrt{ }($ mean square/(number of observations -1$))$.

liver of the Muscovy duck compared with the Pekin duck (2.3fold higher, $P=0.0476$ ). This increase was mainly due to the accumulation of TAG in the liver of Muscovy ducks compared with Pekin ducks (8.8-fold higher, $P=0.0383$ ), whereas the other classes of lipids were not significantly different between the two species. Thus, PL were the major component $(73.1 \%)$ of lipids in the liver of Pekin ducks, whereas, in the liver of Muscovy ducks, the proportion of TAG represented the major part $(62.8 \%)$. Conversely, the hepatic DNA concentration was significantly lower $(P=0.0300)$ in the Muscovy duck than in the Pekin duck.

\section{Glucose metabolism in duck liver slices}

The hepatic glucose uptake was similar for the two species of ducks and represented $11 \%$ of $\left[\mathrm{U}_{-}{ }^{14} \mathrm{C}\right]$ glucose introduced into the medium (Table 3).

In the same way, the complete oxidation of glucose into $\mathrm{CO}_{2}$ similar for the two species of ducks amounted to $21 \%$ of glucose incorporated by the hepatocytes. The part of glucose, which was not involved in the oxidation or lipogenesis (i.e. Krebs intermediaries, glycogen, etc.), was also similar between the two species of ducks. This fraction represented more than $65 \%$ of glucose incorporated by cells.

The intervention of glucose in the lipogenesis pathway could lead to glycerol and FA production. This pathway, although minor in hepatic glucose metabolism (approximately $10 \%$ of glucose incorporated by cells), was $2 \cdot 3$-fold higher in the Muscovy duck than in the Pekin duck $(P=0.0352)$. No significant difference was observed in glycerol formation between the two species of ducks. However, FA synthesis was 3.5 -fold higher $(P=0.0272)$ in the liver slices of the Muscovy duck than in those of the Pekin duck. Then, these FA underwent esterification pathway leading to neutral and polar lipid formation. The incorporation of FA synthesised from glucose into PL corresponded to a minor pathway in the present experimental conditions since it accounted for less than $25 \%$ of glucose involved in the esterification pathway for the two species of ducks. However, esterification into PL was 2-fold higher $(P=0.0100)$ in the liver slices of the Muscovy duck than in those of the Pekin duck. Conversely, FA synthesised from glucose were mainly esterified into TAG since they represented 76.6 and $71.2 \%$ of the total newly synthesised lipids in the liver slices of Muscovy and Pekin ducks, respectively. This esterification into TAG was significantly higher $(+64 \%, P=0.0437)$ in the liver slices of the Muscovy duck than in those of the Pekin duck.

The intensity of secretion of TAG-VLDL was 4-fold higher $(P=0.0061)$ in the liver slices of the Muscovy duck than in those of the Pekin duck.

\section{Linoleic acid metabolism in duck liver slices}

The hepatic LA uptake was $40.4 \%$ higher $(P=0.0163)$ in the Muscovy duck than in the Pekin duck corresponding to approximately 31 and $25 \%$ of $\left[1-{ }^{14} \mathrm{C}\right] \mathrm{LA}$ introduced into the culture medium for Muscovy and Pekin ducks, respectively (Table 4).

The intensity of LA oxidation was significantly lower $(-14 \% ; P=0.0273)$ in the liver slices of the Muscovy duck than in those of the Pekin duck and accounted for 13.4 and $22.2 \%$ of LA incorporated by cells in Muscovy and Pekin

Table 3. Glucose uptake, oxidation and intervention in lipogenesis and esterification into neutral lipids and phospholipids in liver slices from Muscovy and Pekin ducks after $16 \mathrm{~h}$ of incubation

(Mean values with their standard errors for six ducks per group)

\begin{tabular}{|c|c|c|c|}
\hline & Muscovy (nм [U- $\left.{ }^{14} \mathrm{C}\right] \mathrm{glucose} / \mu \mathrm{g}$ DNA per $16 \mathrm{~h}$ ) & Pekin (nM $\left[\mathrm{U}-{ }^{14} \mathrm{C}\right]$ glucose/ $\mu \mathrm{g}$ DNA per $16 \mathrm{~h}$ ) & SE† \\
\hline Intensity of glucose uptakeł & $1091 \cdot 84$ & $976 \cdot 39$ & $55 \cdot 79$ \\
\hline Intensity of glucose oxidation into $\mathrm{CO}_{2}$ & 225.04 & $192 \cdot 84$ & 30.97 \\
\hline Other fractions of glucose $\S$ & $731 \cdot 88$ & $725 \cdot 07$ & $52 \cdot 74$ \\
\hline Intensity of lipogenesis from glucose & $134 \cdot 70$ & $58 \cdot 44^{*}$ & $22 \cdot 69$ \\
\hline Into glycerol & 48.40 & 33.55 & $6 \cdot 61$ \\
\hline Into FA & $86 \cdot 30$ & $24 \cdot 88^{*}$ & $16 \cdot 75$ \\
\hline Intensity of esterification & $134 \cdot 70$ & $58 \cdot 44^{*}$ & $22 \cdot 69$ \\
\hline Into neutral lipids & $103 \cdot 19$ & $41.59^{*}$ & 19.65 \\
\hline Into phospholipids & $26 \cdot 18$ & $11.41^{\star *}$ & $3 \cdot 11$ \\
\hline Intensity of [U- $\left.{ }^{14} \mathrm{C}\right]$ glucose-VLDL secretion & 0.21 & $0.05^{\star \star}$ & 0.03 \\
\hline
\end{tabular}

FA, fatty acids.

Mean value was significantly different from that of the Muscovy ducks: ${ }^{*} P<0.05,{ }^{\star \star} P<0.01$.

$\dagger \mathrm{SE}=\sqrt{ }($ mean square/(number of observations -1$))$.

$\ddagger$ The intensity of glucose uptake corresponded to the sum of radioactivity present in cells, $\mathrm{CO}_{2}$ and VLDL secretion.

$\S$ Other fractions of glucose were estimated by calculating the difference between glucose uptake by hepatocytes and glucose involved in the oxidation or lipogenesis pathway. These fractions contained, among others, intermediaries of the Krebs cycle and glycogen. 
Table 4. Linoleic acid (LA) uptake, oxidation and esterification into neutral lipids and phospholipids in liver slices from Muscovy and Pekin ducks (Mean values with their standard errors for six ducks per group)

\begin{tabular}{|c|c|c|c|}
\hline & Muscovy (nM $\left[1-{ }^{14} \mathrm{C}\right] \mathrm{LA} / \mu \mathrm{g}$ DNA per $16 \mathrm{~h}$ ) & Pekin (nM $\left[1-{ }^{14} \mathrm{C}\right] \mathrm{LA} / \mu \mathrm{g}$ DNA per $\left.16 \mathrm{~h}\right)$ & SE† \\
\hline Intensity of LA uptake & $11 \cdot 30$ & $8.05^{\star}$ & 0.82 \\
\hline Intensity of LA oxidation & 1.50 & $1.74^{\star}$ & 0.07 \\
\hline Into $\mathrm{CO}_{2}$ & 0.09 & $0 \cdot 13$ & 0.03 \\
\hline Into ketone bodies & 1.42 & $1 \cdot 61^{*}$ & 0.05 \\
\hline Intensity of LA esterification & $9 \cdot 71$ & $6 \cdot 24^{*}$ & 0.81 \\
\hline Into neutral lipids & 9.55 & $5 \cdot 82^{\star \star}$ & 0.75 \\
\hline Into phospholipids & 0.17 & $0.45^{\star}$ & 0.09 \\
\hline Intensity of $\left[1-{ }^{14} \mathrm{C}\right] \mathrm{LA}-\mathrm{VLDL}$ secretion & 0.21 & 0.05 & 0.02 \\
\hline
\end{tabular}

Mean value was significantly different from that of the Muscovy ducks: ${ }^{\star} P<0.05,{ }^{\star \star} P<0.01$.

$\dagger \mathrm{SE}=\sqrt{ }($ mean square/(number of observations -1$))$.

$\ddagger$ The intensity of LA uptake corresponded to the sum of radioactivity present in cells, $\mathrm{CO}_{2}$, secreted ketone bodies and VLDL secretion.

ducks, respectively. The complete oxidation of LA into $\mathrm{CO}_{2}$ was similar for the two species but the production of ketone bodies from LA was slightly lower $(-12 \% ; P=0.0251)$ in the liver slices of the Muscovy duck than in those of the Pekin duck.

The esterification of LA into neutral and polar lipids represented more than $75 \%$ of its utilisation by liver slices in both the duck species. Its incorporation into PL accounted for less than $10 \%$ of LA esterified into lipids. Conversely, LA was mainly esterified into neutral lipids in the liver slices since they represented more than $90 \%$ of the total newly synthesised lipids in livers of both Muscovy and Pekin ducks. However, LA esterification was significantly higher $(+56 \% ; P=0.0106)$ in the liver of the Muscovy duck than in that of the Pekin duck. This led to a higher amount of LA esterified into neutral lipids $(+64 \%$, $P=0.0048)$ and a lesser amount of LA esterified into PL (2.7-fold lower, $P=0.0478$ ) in the liver slices of the Muscovy duck than in those of the Pekin duck.

A part of neutral and polar lipids synthesised from LA were incorporated into VLDL particles and secreted into the medium without any significant difference between the two duck species.

\section{Methionine behaviour in duck liver slices}

The uptake of $\left[{ }^{35} \mathrm{~S}\right]$ methionine by liver slices was similar in both the duck species. Its incorporation into total neo-synthesised proteins in hepatocytes was also similar between the two duck species (Table 5). However, $\left[{ }^{35}\right.$ S $]$ methionine incorporation into proteins secreted in the incubation medium was significantly higher $(+46 \%, P=0.0362)$ in the liver slices of the Muscovy duck than in those of the Pekin duck.

In the same way, the incorporation of $\left[{ }^{35} \mathrm{~S}\right]$ methionine into neo-synthesised albumin present in hepatocytes was similar between the two duck species, whereas the intensity of secretion of $\left[{ }^{35} \mathrm{~S}\right]$ albumin was 1.8 -fold higher $(P=0.0317)$ in the liver slices of the Muscovy duck than in those of the Pekin duck.

The amount of intracellular neo-synthesised $\left[{ }^{35} \mathrm{~S}\right] \mathrm{apoB}$ was $2 \cdot 4$-fold higher $(P=0 \cdot 0144)$ in the liver slices of the Muscovy duck than in those of the Pekin duck. The secretion of $\left[{ }^{35} \mathrm{~S}\right] \mathrm{apoB}$ as part of $\left[{ }^{35} \mathrm{~S}\right] \mathrm{apoB}-\mathrm{VLDL}$ was very low but was also 2-fold higher $(P=0.0128)$ in the liver slices of the Muscovy duck than in those of the Pekin duck.

\section{Discussion}

\section{Zootechnical parameters}

In the present experimental conditions, ducks were fed ad libitum to precise the influence of species on the liver lipid metabolism in basal dietary conditions. Under these conditions, for the same amount of feed ingested during the growing period for both the species, the weight of the liver and its lipid content (mainly TAG content) was higher in the Muscovy duck than in the Pekin duck; this is in agreement with the previous data of Chartrin et al. ${ }^{(7)}$. These differences between species could be explained by net differences in the use of energy nutrients between genotypes, suggesting a better efficiency in nutrient digestion and absorption or conversion into lipids in the Muscovy duck than in the Pekin duck, which would have a relatively weak use of energy nutrients preferentially stored in the adipose tissues ${ }^{(6)}$. In parallel, the lower hepatic content of DNA of the Muscovy duck would suggest a tendency for a cellular hypertrophy of the liver as previously reported during the overfeeding period by Hermier et al. ${ }^{(14)}$. All these results suggested that, even in basal dietary conditions, the Muscovy duck had a tendency for hepatic steatosis.

\section{Fat metabolism in the liver of ducks}

To compare fat metabolism in the liver of Muscovy and Pekin ducks, we used the ex vivo system of metabolic labelling of incubated liver slices. This system was chosen so as to retain the normal cellular architecture of the liver, to avoid the de-differentiation of hepatocytes and to keep functional regulatory effects as occurring under in vivo conditions ${ }^{(15)}$.

\section{Glucose metabolism}

The similar level of glucose uptake by the liver slices, in the two species of ducks, suggests that the number and/or the activity of the GLUT2 were not rate-limiting steps of the hepatic glucose metabolism. 
Table 5. Uptake and production of $\left[{ }^{35} \mathrm{~S}\right]$ methionine $\left(\left[{ }^{35} \mathrm{~S}\right] \mathrm{met}\right)$ total proteins, albumin, apoB and apoB-VLDL present in cells and the medium of liver slices from Muscovy and Pekin ducks incubated for $16 \mathrm{~h}$

(Mean values with their standard errors for six ducks per group)

\begin{tabular}{|c|c|c|c|}
\hline & Muscovy (pmol $\left[{ }^{35} \mathrm{~S}\right] \mathrm{met} / \mu \mathrm{g}$ DNA per $\left.16 \mathrm{~h}\right)$ & Pekin (pmol $\left[{ }^{35} \mathrm{~S}\right] \mathrm{met} / \mu \mathrm{g}$ DNA per $16 \mathrm{~h}$ ) & SE† \\
\hline Intensity of methionine uptake & 24.74 & $20 \cdot 33$ & 1.84 \\
\hline \multicolumn{4}{|l|}{ Production of ${ }^{35} \mathrm{~S}$-labelled total proteins } \\
\hline In the liver & $2 \cdot 52$ & $2 \cdot 34$ & 0.38 \\
\hline In the medium & 2.46 & $1.69^{\star}$ & 0.24 \\
\hline \multicolumn{4}{|l|}{ Production of $\left[{ }^{35} \mathrm{~S}\right]$ albumin } \\
\hline In the liver & 0.23 & 0.15 & 0.05 \\
\hline In the medium & 0.34 & $0 \cdot 19^{\star}$ & 0.05 \\
\hline Production of $\left[{ }^{35}\right.$ S]apoB in the liver & 0.09 & $0.04^{*}$ & 0.39 \\
\hline Production of $\left[{ }^{35}\right.$ S]apoB-VLDL in the medium & 0.004 & $0.002^{*}$ & 0.05 \\
\hline
\end{tabular}

${ }^{*}$ Mean value was significantly different from that of the Muscovy ducks $(P<0.05)$.

$\dagger \mathrm{SE}=\sqrt{ }($ mean square/(number of observations -1$))$.

The intensity of glucose oxidation into $\mathrm{CO}_{2}$, determined in the present experimental conditions (approximately $20 \%$ of glucose incorporated by hepatocytes), was largely inferior to that determined by Goodridge ${ }^{(16)}$ on the liver slices of growing chicks $(57 \%)$. Such discrepancy could be explained by technical differences between experiments. Indeed, Goodridge ${ }^{(16)}$ performed his experiment for only $1 \mathrm{~h}$ and did not include FA in the medium, glucose being the only energetic substrate. On the other hand, the intensities of both the oxidation and storage pathways of glucose were similar between the two species, showing no significant effect of species on these metabolic pathways.

Glucose that was not used for oxidative phosphorylation or stored into tissues was used as a precursor for lipogenesis (6-12\% of incorporated glucose), in agreement with the results of Bickerstaffe et al. ${ }^{(17)}$ on perfused liver of chicken. This fraction of glucose would be mainly esterified into TAG, as previously shown by Cross \& Dodds $^{(18)}$ using laying hen hepatocytes and by Evans ${ }^{(19)}$ using duck liver slices. However, the higher hepatic lipogenic capacity of the Muscovy duck compared with the Pekin duck resulted in higher synthesis of FA and their subsequent esterification as TAG. This confirmed the higher activity of the FA synthase determined in this species by comparison with the Pekin duck as previously reported by Baéza et al. ${ }^{(8)}$. Thus, with an ad libitum basal diet, the liver of the Muscovy duck had already the capacity to use twice better the glucose for lipid synthesis better than that of the Pekin duck.

\section{Linoleic acid metabolism}

The intensity of LA uptake by duck liver slices (representing approximately $25-30 \%$ of FA introduced into the medium) was similar to that reported for oleic acid with perfused chicken liver ${ }^{(17)}$. Studies in different mammalian species have shown that the uptake of long-chain FA across the plasma membrane would occur according to three distinct mechanisms: a passive diffusion through the membrane bilayer $^{(20)}$; a protein-facilitated transfer ${ }^{(21)}$; an FA diffusion in protein-defined annular lipid domains, which is not carrier mediated $^{(22)}$. One of these mechanisms could be more efficient in the Muscovy duck than in the Pekin duck. Another hypothesis would be a substantial vascularisation of the liver in the Muscovy duck compared with that of the Pekin duck, leading to a higher supply of LA to the liver. However, all these mechanisms have never been studied in duck liver.

The intensity of LA oxidation was relatively low (about $13-23 \%$ of LA taken up by cells), and was dominated by the ketone-body production (more than $90 \%$ of oxidised LA) confirming similar observations in isolated chick hepatocytes ${ }^{(23)}$. The ketone-body production was higher in the liver of the Pekin duck than in that of the Muscovy duck, leading to a higher total oxidation of LA in this species. Recently, the carnitine palmitoyl transferase 1, which catalysed FA transfer into mitochondria (rate-limiting step of FA oxidation), has been characterised in the liver of chicken and appeared regulated by genotypes (fat and lean) and nutritional status (fed and fasted) ${ }^{(24)}$, suggesting that the high lipogenic activity found in Muscovy ducks could exert an inhibitory effect, through malonyl-CoA production, on the activity of carnitine palmitoyl transferase 1 and, consequently, on $\beta$-oxidation rates.

LA was mainly focused towards the esterification pathway in both the duck species (more than $75 \%$ of incorporated LA), in agreement with the data of Bickerstaffe et al. ${ }^{(17)}$ on perfused liver of chicken and those of Guillot et al. ${ }^{(23)}$ on isolated hepatocytes of chicken, showing that more than $80 \%$ of palmitic acid incorporated by hepatocytes were esterified essentially as part of TAG.

A larger part of both glucose and LA was oriented towards the esterification pathway in the liver of the Muscovy duck compared with that of the Pekin duck. Mechanisms involved in favour of the FA esterification pathway differed probably between these two nutrients. The larger part of glucose that entered into the lipogenic pathway in the liver of Muscovy ducks was probably linked with a higher activity of enzymes implied in this pathway, notably FA synthase activity ${ }^{(6)}$. By contrast, the larger part of LA involved in the esterification pathway in the Muscovy duck liver was probably only the consequence of a higher uptake of this FA by the liver of this duck species.

\section{Capacity of VLDL secretion}

New synthesised TAG could then be either assembled with one apoB molecule to form VLDL (a lipoprotein rich in 
TAG) or transitorily stored as lipid droplets ${ }^{(3)}$ in the cytosol. In the present experimental conditions, the higher capacity of apoB synthesis and secretion as part of apoB-VLDL and the higher secretion of TAG provided from $\left[\mathrm{U}-{ }^{14} \mathrm{C}\right]$ glucose esterification and transported by VLDL of Muscovy duck livers did not confirm the previous data of Hermier et al. ${ }^{(5)}$, showing a higher VLDL concentration in the plasma of the Pekin duck than in that of the Muscovy duck. However, these discrepancies could be explained by a more efficient rate of lipoprotein clearance by the liver and extrahepatic tissues such as adipose tissues in the Muscovy duck than in the Pekin duck in vivo, clearance that cannot be shown in the present experimental conditions.

In the present experimental conditions, the higher secretion of VLDL by the liver of Muscovy ducks compared with that of Pekin ducks can be explained by the higher LA uptake and the higher lipogenesis intensity stimulating VLDL secretion as previously demontrated ${ }^{(25)}$. However, in such conditions, the secretion of VLDL by Muscovy ducks seemed to be overwhelmed and insufficient to avoid TAG accumulation in the liver. A different hypothesis can be proposed to explain this inadequate secretion such as a defect in mechanisms of VLDL particles assembly and/or of VLDL secretion. The TAG hydrolase and the microsomal transfer protein have been recently proposed as regulatory factors involved in these mechanisms ${ }^{(26,27)}$ and their role in hepatic lipid metabolism of ducks could be investigated.

In conclusion, the liver-slice model allowed us to compare FA metabolism and VLDL production between Muscovy and Pekin ducks. We clearly demonstrated that the ability of the ad libitum-fed Muscovy duck to synthesise TAG from glucose was 2-fold higher than that of the Pekin duck. In the same way, the uptake of LA was also 2-fold higher in the liver of the Muscovy duck than in that of the Pekin duck, leading to a 2-fold higher production of TAG from this FA. However, the ability of the liver of the Muscovy duck to secrete VLDL, although higher than that of the Pekin duck, stayed insufficient to avoid hepatic TAG accumulation. These results should shed light on the metabolic regulations that might underlie susceptibility to hepatic steatosis in the human liver.

\section{Acknowledgements}

We thank the 'Conseil Général des Landes', the 'Comité Interprofessionnel des Palmipèdes à Foie Gras' and the Department of 'Physiologie Animale et Systèmes d'Elevage' for financing the present work. We also thank the technical staff of INRA Artiguères and Theix for rearing ducks. We are grateful to Marinette Brunel, Francoise Duboisset and Christiane Legay for their excellent technical assistance. G. S. received a doctoral studentship from the 'Conseil Général des Landes'. E. B. and S. D. had the initial idea for the study and were responsible for obtaining financing. G. S. and D. G. were responsible for experimental management, data analysis, interpretation, statistical analysis and manuscript writing. D. D. and D. B. contributed to the design and the realisation of the study. All the authors critically reviewed the manuscript for intellectual content. There were no conflicts of interest.

\section{References}

1. Pilo B \& George JC (1983) Diurnal and seasonal variations in liver glycogen and fat in relation to metabolic status of liver and $m$. pectoralis in the migratory starling Sturnus roseus, wintering in India. Comp Biochem Physiol 74A, 601-604.

2. Pearce J (1977) Some differences between avian and mammalian biochemistry. Int J Biochem 8, 269-279.

3. Gruffat D, Durand D, Graulet B \& Bauchart D (1996) Regulation of VLDL synthesis and secretion in the liver. Reprod Nutr Dev 36, 375-389.

4. Gibbons GF, Bartlett SM, Sparks CE \& Sparks JD (1992) Extracellular fatty acids are not utilized directly for the synthesis of very-low-density-lipoprotein in primary cultures of rat hepatocytes. Biochem J 287, 749-753.

5. Hermier D, Guy G, Guillaumin S, Davail S, André JM \& HooParis R (2003) Differential channelling of liver lipids in relation to susceptibility to hepatic steatosis in two species of duck. Comp Biochem Physiol Biochem Mol Biol 135B, 663-675.

6. Davail S, Rideau N, Guy G, André JM, Hermier D \& Hoo-Paris R (2003) Hormonal and metabolic responses to overfeeding in three genotypes of ducks. Comp Biochem Physiol 134A, $707-715$.

7. Chartrin P, Bernadet MD, Guy G, Mourot J, Hocquette JF, Rideau N, Duclos MJ \& Baéza E (2006) Does overfeeding enhance genotype effects on liver ability for lipogenesis and lipid secretion in ducks. Comp Biochem Physiol 145A, 390-396.

8. Baéza E, Rideau N, Chartrin P, et al. (2005) Canards de Barbarie, Pékin et leurs hybrides: aptitudes à l'engraissement. INRA, Prod Anim 18, 131-141.

9. Folch J, Lees M \& Sloane Stanley GH (1957) A simple method for the isolation and purification of total lipides from animal tissues. J Biol Chem 226, 497-509.

10. Sébédio JM, Juanéda P, Dobson G, Ramilison I, Martin JC, Chardigny JM \& Christie WW (1997) Metabolites of conjugated isomers of linoleic acid (CLA) in the rat. Biochem Biophys Acta 1345, 5-10.

11. Kaluzni MA, Duncan LA, Merritt MV \& Epps DE (1985) Rapid separation of lipid classes in high yield and purity using bonded phase columns. J Lipid Res 26, 135-140.

12. Gruffat-Mouty D, Graulet B, Durand D, Samson-Bouma ME \& Bauchart D (1999) Apolipoprotein B production and very low density lipoprotein secretion by calf liver slices. $J$ Biochem 126, $188-193$.

13. Labarca C \& Paigen K (1980) A simple, rapid and sensitive DNA assay procedure. Anal Biochem 102, 344-352.

14. Hermier D, Salichon MR, Guy G, Peresson R, Mourot J \& Lagarrigue $S$ (1999) La stéatose hépatique des palmipèdes gavés: bases métaboliques et sensibilité génétique. INRA, Prod Anim 12, 265-271.

15. Olinga P, Meijer DKF, Slooff MJH \& Groothuis GMM (1997) Liver slices in in vitro pharmacotoxicology with special reference to the use of human liver tissue. Toxicol In Vitro 12, 77-100.

16. Goodridge AG (1968) Conversion of $\left[\mathrm{U}^{14}{ }^{14} \mathrm{C}\right]$-glucose into carbon dioxide, glycogen, cholesterol and fatty acids in liver slices from embryonic and growing chicks. Biochem J 108, 655-661.

17. Bickerstaffe R, West CE \& Annison EF (1970) Lipid metabolism in the perfused chicken liver. Biochem J 118, 427-431.

18. Cross KE \& Dodds PF (1988) The use of two populations of hepatocytes with different triacylglycerol contents as a model to study the accumulation of liver lipid in the laying hens. Biochem J 255, 259-265.

19. Evans AJ (1972) In vitro lipogenesis in the liver and adipose tissues of the female Aylesbury duck at different ages. Br Poult Sci 13, 595-602.

20. Zakim D (1996) Fatty acids enter cells by simple diffusion. Proc Soc Exp Biol Med 212, 5-14. 
21. Hirsch D, Stahl A \& Lodish HF (1998) A family of fatty acid transporters conserved from mycobacterium to man. Proc Natl Acad Sci USA 95, 8625-8629.

22. Bojesen IN \& Bojesen E (1999) Sheep erythrocyte membrane binding and transfer of long-chain fatty acids. J Membr Biol 171, 141-149.

23. Guillot E, Legrand P \& Lemarc P (1997) Octanoate metabolism in primary culture of chicken hepatocytes: evidence for high-capacity octanoate esterification. Comp Biochem Physiol 118B, 249-256.

24. Skiba-Cassy S, Collin A, Chartrin P, Médale F, Simon J, Duclos MJ \& Tesseraud S (2007) Chicken liver and muscle carnitine palmitoyltransferase 1: nutritional regulation of messengers. Comp Biochem Physiol 147B, 278-287.

25. Lewis GF (1997) Fatty acid regulation of very low density lipoprotein production. Curr Opin Lipidol 8, 146-153.

26. Gilham D \& Lehner R (2006) Provision of lipids for very lowdensity lipoprotein assembly. In Biochemistry of Atherosclerosis, pp. 121-149. New York: Springer.

27. Wetterau JR, Lin MCM \& Jamil H (1997) Microsomal triglyceride transfer protein. Biochim Biophys Acta 1345, 136-150. 